\title{
A paisagem da cafeicultura na crise da escravidão: as pinturas de Nicolau Facchinetti e Georg Grimm*
}

\author{
Rafael de Bivar Marquese**
}

\section{Resumo}

Dentre os pintores oitocentistas que registraram a paisagem da cafeicultura escravista do Vale do Paraíba, os mais notáveis foram certamente o italiano Nicolau Facchinetti (18241900) e o alemão Georg Grimm (1846-1887). Facchinetti começou a pintar suas paisagens em fins da década de 1860, mas o fez sobretudo entre 1875 e 1881. Grimm, por sua vez, trabalhou na composição de seus óleos na década de 1880. 0 artigo examinará os princípios que regeram a conformação das paisagens dos dois pintores e a natureza do diálogo que estabeleceram com a crise da escravidão brasileira.

\section{Palavras-chave}

escravidão, cafeicultura, Vale do Paraíba, pintura de paisagem, Nicolau Facchinetti, Georg Grimm.

* o artigo, originalmente apresentado ao I SEMINÁRIO DE HISTÓRIA DO CAFÉ: HISTÓRIA E CULTURA MATERIAL (promovido em novembro de 2006 pelo Museu Paulista da USP em Itu, São Paulo), faz parte do projeto "The world of the plantation and the world the plantations made: the "great house tradition' in the american landscape", que conta com uma Collaborative Research Grant da Getty Foundation. Agradeço os comentários de Dale Tomich e Tâmis Parron, afora a gentileza de Roberto Guião de Souza Lima, Leila Alegrio e Adriano Novaes, que me franquearam a consulta de seus acervos documentais.

** professor no Departamento de História da FFLCH-USP. 
revista do ieb n 44 p. 55-76 fev 2007

\section{The landscape of the coffee plantations in the crisis of slavery: the paintings by Nicolau Facchinetti and Georg Grimm}

Rafael de Bivar Marquese

Abstract

Among the painters of the nineteenth century that registered the landscape of the slave coffee plantations of the Vale do Paraíba, the most remarkable were certainly the Italian Nicolau Facchinetti (1824-1900) and the German Georg Grimm (18461887). Facchinetti started to paint his landscapes by the end of the 1860's, although his main works were painted between 1875 and 1881. Grimm, on the other hand, worked on the composition of his canvases in the 1880's. This paper aims to examine the principles that structured the landscapes painted by both of them, and the nature of the dialogue they established with the crisis of the Brazilian slavery.

\section{Keywords}

slavery, coffee plantations, Vale do Paraíba, landscape painting, Nicolau Facchinetti, Georg Grimm. 


\section{Pintura de paisagem e tensões sociais}

Como há um bom tempo indicam os especialistas, a pintura paisagista emergiu na Europa no século XV antes como idéia, como um "modo de ver", do que como um gênero específico de representação visual ${ }^{1}$. Com isso, ressaltam que o conceito de paisagem não é universal, isto é, não se fez presente em todas as sociedades humanas. Apenas em determinados tempos e espaços ele serviu como um constructo e uma forma de representação para dar conta das relações entre homem e meio ambiente. Ainda que a interpretação sobre a especificidade européia tenha sido reavaliada por aqueles que apontaram a existência de outras “civilizações paisagísticas" ao longo da história ${ }^{2}$, os pesquisadores concordam a respeito do peso que o conceito e a prática adquiriram na Europa e em seus prolongamentos ultramarinos a partir do século XVII.

A última data certamente não é fortuita. W.J.T. Mitchell chamou a atenção para o fato, ao escrever que "as características semióticas da paisagem ["vasta rede de códigos culturais" que vai além do simples gênero pictórico] e as narrativas históricas que gerou se ajustam à perfeição ao discurso do imperialismo", que não raro apresenta a própria expansão da paisagem como "parte de um desenvolvimento inevitável e progressivo na história, um avanço da ‘cultura' e ‘civilização' sobre um espaço 'natural' que, em si, é narrado como "natural'”3. A conexão entre expansão imperial e os códigos culturais da paisagem levou Mitchell a salientar como a última está diretamente imbricada nas lutas sociais e nas relações de poder. Por essa razão, prossegue, a paisagem deve ser encarada, sobretudo, como verbo, "como um processo pelo qual as identidades sociais e subjetivas são formadas".

As relações entre as paisagens e as lutas sociais, no entanto, adquiriram múltiplos significados, conforme os diferentes

1 GOMBRICH, E.H. A teoria renascentista da arte e a ascensão da paisagem.

In: Norma e forma: estudos sobre a arte da renascença. São Paulo:

Martins Fontes, 1990; e COSGROVE, Denis. Social formation and symbolic landscape. New Ed. Madison: The University of Wisconsin Press, 1996.

2 MENESES, Ulpiano Toledo Bezerra de. A paisagem como fato cultural. In: YÁZIGI, Eduardo (Org.). Turismo e paisagem. São Paulo: Contexto, 2002. p. 31.

3 MITCHELL, W.J.T. (Ed). Landscape and power. Chicago: The University of Chicago Press, 1994. p. 17.

4 Ibid. p. 1. 
contextos históricos em que foram ativadas ${ }^{5}$. 0 objetivo deste artigo é examinar um desses contextos, no caso o da sociedade escravista brasileira em sua crise decisiva. Noutros termos, pretendo analisar a pintura de paisagem das fazendas de café do Vale do Paraíba nas duas últimas décadas de vigência do cativeiro no Brasil.

0 foco recairá sobre dois pintores, Nicolau Facchinetti e Georg Grimm, certamente os mais notáveis que representaram as fazendas do Vale. Facchinetti, nascido em 1824, em Treviso, veio para o Brasil em 1849, aqui falecendo meio século depois, em 1900. Grimm, por sua vez, além de mais novo (nasceu em 1846, na Baviera), residiu por um período bem menor no Brasil, de 1878 a 1887, ano de seu regresso à Europa e de seu falecimento. Tratava-se, de todo modo, de artistas que vieram para a América já formados em certos cânones da arte européia. Dentro do panorama das artes plásticas no Brasil do século XIX, os dois se destacaram como paisagistas que operaram à margem da Academia Imperial de Belas Artes, ainda que tenham participado das exposições promovidas pela instituição - caso de Facchinettti - e, como no caso de Grimm entre 1882 e 1884, lecionado por breve tempo nela. Um outro ponto que os unifica é o fato de terem composto diversas paisagens de grandes fazendas de café no Vale do Paraíba nas décadas de 1870 e 1880, sempre por encomenda dos senhores de escravos da região.

0 gênero da pintura - ou mesmo da fotografia - de paisagem não foi da especial predileção da classe senhorial do Vale do Paraíba. Dentro dos circuitos de consumo de artefatos visuais no Império do Brasil, houve um amplo predomínio dos retratos a óleo até meados do século e, após a década de 1860, dos retratos fotográficos. Mauad registra que, nas coleções de fotos de família tão correntes entre os senhores de escravos do Vale do Paraíba, as fazendas não figuravam nos álbuns, "não eram tema para retrato" ${ }^{6}$. É certo que, em determinados casos, inseriramse representações das fazendas em pinturas parietais de casas

5 MITCHELL, W.J.T. (Ed). Landscape and power. Chicago: The University of Chicago Press, 1994. p.1 ; e COSGROVE, Denis; DANIELS, Stephen (Ed.). The iconography of landscape: essays on the symbolic representation, design and use of past environments. Cambridge: Cambridge University Press, 1987.

6 MAUAD, Ana Maria. Imagem e auto-imagem do Segundo Reinado. In: ALENCASTRO, Luiz Felipe de (Org.). História da vida privada no Brasil 2. Império: a corte e a modernidade nacional. São Paulo: Companhia das Letras, 1997. p. 222; e MAUAD, Ana Maria. Entre retratos e paisagens: modos de ver e representar no Brasil oitocentista. Studium, Campinas, v. 15, 2004. Disponível em: http://www.studium.iar.unicamp.br/15/01.html. Acesso em: 27 fev. 2007. 
urbanas, como se pode observar ainda hoje no salão de jantar da família Álvares de Magalhães, em São José do Barreiro, São Paulo $^{7}$, mas, diante do conhecimento atualmente disponível, pode-se afirmar que a prática não foi muito corrente.

Daí o interesse que tem, para o pesquisador, a série de paisagens de fazendas compostas por Nicolau Facchinetti e Georg Grimm a partir da década de 1870 . Ao contrário do primeiro pintor, que foi recentemente objeto de uma bela e ampla exposição ${ }^{8}$, o segundo não tem recebido grandes atenções dos historiadores da arte. 0 catálogo mais completo de que dispomos para a obra de Grimm foi publicado há quase três décadas, e várias pinturas de fazenda que lhe são atribuídas (Oriente, em Valença; Boa Vista, em Bananal; Sant'Anna do Calçado, em São José do Rio Preto) não constaram do levantamento pioneiro de Carlos Levy (1980) ${ }^{9}$. Algo semelhante ocorre com Facchinetti: há referências a diferentes fazendas pintadas pelo artista italiano (Alpes, Monte Verde, Ribeirão Dourado), mas sem mais informações a respeito de localização e data de composição.

Mesmo diante dessas lacunas e incertezas, o repertório de informações que essas imagens trazem é altamente significativo. Tenho trabalhado com elas em um projeto coletivo mais amplo que examina a paisagem e a arquitetura das zonas de plantations escravistas que se destacaram nos quadros da economia mundial capitalista no século XIX, isto é, o cinturão açucareiro cubano de Matanzas-Cienfuegos-Trinidad, o cinturão algodoeiro do baixo vale do rio Mississippi e o Vale do Paraíba cafeeiro $^{10}$. Os quadros de Facchinetti e Grimm são, para tanto, fontes privilegiadas, por fornecerem diversos elementos para a análise da implantação arquitetônica das fazendas de café do Vale do Paraíba e dos códigos culturais mobilizados para a conformação de suas paisagens. No entanto, no trato com essas

70 café: catálogo da exposição realizada na Praça do Banco Real. São Paulo: Banco Real-ABN-AMRO Bank, 2000. p.64.

8 MARTINS, Carlos; PICCOLI, Valéria (Org.). Facchinetti. Rio de Janeiro: CCBB, 2004.

9 LEVY, Carlos Roberto Maciel. O grupo Grimm: paisagismo brasileiro no século XIX. Rio de Janeiro: Edição Pinakotheke, 1980.

10 MARQUESE, Rafael de Bivar. Moradia escrava na era do tráfico ilegal: senzalas rurais no Brasil e em Cuba, c.1830-1860. Anais do Museu Paulista - História e Cultura Material, Nova Série, São Paulo, v. 13, n. 2, p. 165-188, jul.-dez. 2005; e MARQUESE, Rafael de Bivar. Revisitando casas-grandes e senzalas: a arquitetura das plantations escravistas americanas no século XIX. Anais do Museu Paulista - História e Cultura Material, Nova Série, São Paulo, v. 14, n. 1, p. 11-57, jan.-jun. 2006. 
fontes, determinadas perguntas que têm sido perquiridas no caso de representações compostas em outras sociedades escravistas do Novo Mundo ${ }^{11}$ permaneceram sem resposta. 0 que Facchinetti e Grimm estavam dizendo com essas pinturas? 0 que elas revelam sobre o mundo em que atuaram seus autores? Como se inscreveram no jogo de forças econômicas, sociais, políticas e culturais do Brasil de fins no século XIX? Em resumo, por quais meios funcionaram como prática cultural?

0 artigo é um primeiro esforço para enfrentar essas questões e, portanto, não deve ser encarado como resultado final de uma investigação concluída. Como se viu, a série completa das pinturas de Facchinetti e Grimm para as fazendas de café do Vale do Paraíba não foi estabelecida; há pouca informação sobre as encomendas e a aquisição das obras, ou sobre as fazendas representadas e seus proprietários. Diante dessas lacunas, apresento basicamente um conjunto de hipóteses. Procurarei desenvolver a idéia de que o gênero da pintura de paisagem foi mobilizado pela classe senhorial do Vale do Paraíba como uma resposta direta à crise da escravidão negra no Império do Brasil.

\section{A paisagem da cafeicultura no pincel de Facchinetti e Grimm}

Em abril de 1875, Facchinetti finalizou uma paisagem da fazenda Flores do Paraíso (Fig. 1). 0 quadro lhe fora encomendado pelo segundo barão do Rio Preto, Domingos Custódio Guimarães, que, havia pouco, em 24 de setembro de 1874, recebera o título nobiliárquico. A fazenda Flores do Paraíso havia sido montada pelo seu pai - homônimo - em meados do século XIX no coração da cafeicultura fluminense, no então município de Valença. Domingos Custódio Guimarães pai nascera em São João del Rei em 1800, sendo agraciado com o título de barão em 1854 e de visconde do Rio Preto em 1867. A origem da fortuna de Custódio Guimarães datava da década de 1820, quando, em sociedade com o também mineiro José Francisco de Mesquita, fundou a companhia Mesquita \&t Guimarães, especializada no abastecimento de carne para a Corte Imperial e na venda de

11 MANTHORNE, Katherine. Plantation pictures in the Americas, circa 1880: land, power, and resistance. Neplanta: views from South, v. 2, n. 2, p. 317-53, 2001; VLACH, John Michael. The planter's prospect: privilege \& slavery in plantations paintings. Chapel Hill: The University of North Carolina Press, 2002; TOMICH, Dale. Between image and text: clues, documentation and representation of the cuban Ingenio, 1820-1860. Texto apresentado ao Seminário PLACE, EVENT, AND NARRATIVE CRAFT: METHOD AND MEANING IN MICROHISTORY. Santa Fé, New México, School of American Research, 2005. 
escravos africanos serra acima ${ }^{12}$. Na década seguinte, inverteu seus capitais acumulados no comércio e no tráfico na compra de terras e no plantio de café na região do vale do Rio Preto (afluente do Paraíba), divisa das províncias do Rio de Janeiro e de Minas Gerais. 0 centro de suas atividades foi a sesmaria das Flores, adquirida em 1843, onde levantou a sede da Flores do Paraíso, finalizada dez anos depois ${ }^{13}$. Conhecida como a "jóia de Valença”, a fazenda notabilizou-se no século XIX pela adoção de uma série de inovações técnicas, como iluminação a gás, terreiros asfaltados e um avançado maquinário de beneficiamento cafeeiro implantado no início da década de 1860.

Ao falecer, em 1868, o visconde do Rio Preto legou a seus familiares uma imensa fortuna, composta de diversos prédios urbanos em Valença e na Corte, cinco grandes unidades produtivas cafeeiras da região de Valença e quase um milhar de escravos, dos quais mais da metade residia na fazenda Flores do Paraíso (Inventário do visconde do Rio Preto, 1869). Esta última, que ficou com a viscondessa por ocasião da partilha da herança do marido, passou, com sua morte em 1873, para as mãos de Custódio Guimarães filho; cunhado e irmã ficaram com as fazendas satélite, como a Barra das Flores e a Santa Bárbara (Inventário da viscondessa do Rio Preto, 1873). Portanto, a encomenda para que Facchinetti pintasse a fazenda Flores do Paraíso ocorreu apenas dois anos após Custódio Guimarães tê-la recebido como herança, e menos de um ano após virar barão. Seu cunhado, Domingos Theodoro de Azevedo Junqueira, também requisitou nesses anos os serviços de Facchinetti, no caso para a composição de uma vista a vôo de pássaro de São Tomé das Letras, em Minas Gerais. Nessa altura (meados da década de 1870), era crescente o prestígio do pintor italiano no mercado da Corte, como atesta sua volumosa produção no período ${ }^{14}$.

12 LENHARO, Alcir. As tropas da moderação: o abastecimento da Corte na formação política do Brasil, 1808-1842. 2. ed. Rio de Janeiro: SMCTE/ Prefeitura da Cidade do Rio de Janeiro, 1993; TAUNAY, Affonso. História do café no Brasil. Rio de Janeiro: DNC, 1939. v.5, p. 183-4; FRAGOSO, João Luis Ribeiro; FERREIRA, Roberto Guedes. Tráfico interno de escravos e relações comerciais no centro-Sul, séc.XVIII-XIX. Brasília: IPEA/LIPHIS, 2001. CD-ROM.

13 MUNIZ, Célia Maria Loureiro. Os donos da terra: um estudo sobre a estrutura fundiária do Vale do Paraíba fluminense, século XIX. 1979. $184 \mathrm{f}$. Dissertação (Mestrado) - Universidade Federal Fluminense, Niterói, 1979. p. 80-5; ALEGRIO, Leila Vilela. Janelas e portas do café. Vale do Paraíba fluminense. Rio de Janeiro: SESC/RJ, 2004. p. 33.

14 MARTINS, Carlos; PICCOLI, Valéria (Org.). Facchinetti. Rio de Janeiro: CCBB, 2004. p. 14-7. 
A paisagem da Flores do Paraíso, parte da construção da auto-imagem do novo barão do Rio Preto ao registrar o centro de suas atividades, obedeceu à risca os padrões formais que Facchinetti seguiu ao longo de sua carreira, como se pode depreender com base no estudo de Valéria Piccoli: a estruturação da cena representada em três planos, "que variam progressivamente em intensidade tonal, sendo o mais escuro o plano mais próximo ao observador"; a ausência de personagens; a ênfase nos elementos topográficos; a perseguição de "uma objetividade quase científica, reportando-se à paisagem real”; a adoção de um ponto de vista que permitisse obter efeito cenográfico, o que, por um lado, reforçava "a sensação panorâmica da cena representada", mas, por outro, resultava num extremo detalhismo nos dois primeiros planos, ressaltando-se a reputação de miniaturista que tanto marcou o pintor no século XIX ${ }^{15}$.

0 óleo em questão foi organizado por Facchinetti em quatro partes retangulares, rigorosamente simétricas, com uma evidente contraposição vertical entre lados esquerdo e direito do quadro, e, horizontal, entre céu e terra. 0 uso da luz busca dar conta do efeito do nascer do sol, e, por isso, o céu é dividido em um lado (esquerdo) com acentuada luminosidade clara e um outro (direito) mais escuro. A contraposição vertical na metade inferior do quadro segue lógica distinta do que ocorre em sua parte superior, e busca apreender o próprio processo de formação da paisagem do Vale do Paraíba. Assim, o lado esquerdo inferior é estruturado pelo eixo diagonal da estrada que ligava a fazenda ao município de Valença, sendo o enquadramento à direita dado pelo ribeirão Manoel Pereira, afluente do Rio Preto; ao fundo, vê-se o mar de morros típico da região iluminado pelos primeiros raios do dia. 0 tema desse quarto é a transformação da mata atlântica em pasto, e, não por acaso, a passagem de uma a outro é marcada pela roçada em terreno de derrubada que Facchinetti anotou no ponto mais à esquerda. 0 lado direito inferior focaliza a sede da fazenda, com seu partido palladiano em $\mathrm{U}$, sua casa de vivenda monumental e sua enorme senzala em quadra ${ }^{16}$. A unidade escravista se encontra em plena operação, como indicam a fumaça das caldeiras do engenho de cana e o café espalhado no terreiro.

Afora o conjunto arquitetônico, um segundo elemento chama a atenção nesse quarto da pintura: a representação do cafezal

15 MARTINS, Carlos; PICCOLI, Valéria (Org.). Facchinetti. Rio de Janeiro: CCBB, 2004. p.23-33.

16 MARQUESE, Rafael de Bivar. Revisitando casas-grandes e senzalas: a arquitetura das plantations escravistas americanas no século XIX. Anais do Museu Paulista - História e Cultura Material, Nova Série, São Paulo, v. 14, n. 1, p. 11-57, jan.-jun. 2006. 
localizado atrás da sede. 0 ocre do morro contrasta vivamente com o verde da pastagem defronte ao terreiro pavimentado, atraindo imediatamente o olhar. Então, uma observação cuidadosa do morro indica a presença das fileiras verticais dos pés de café, em processo de franca erosão, o mesmo ocorrendo com a colina à esquerda. Há, aqui, um movimento aparentemente contraditório: se o objetivo da encomenda era glorificar o segundo barão do Rio Preto por meio da representação da grandiosidade do centro de suas atividades econômicas, como entender o registro explícito de devastação ambiental contido na imagem do único cafezal presente na pintura?

Para sorte nossa e azar do barão, temos à disposição uma série de três inventários da Flores do Paraíso, todos lavrados em datas muito próximas por ocasião das mortes do pai (1869), da mãe (1873) e do filho (1876), no mesmo intervalo de tempo da composição do óleo de Facchinetti (1875) ${ }^{17}$. No momento, interessam as anotações referentes aos cafezais. No inventário do visconde, de 1869, foram arrolados cerca de 319.000 pés de café, com idades e preços distintos. Como se sabe, a avaliação dos cafezais nas fazendas vale-paraibanas oitocentistas seguia uma conformação gráfica equivalente a um U invertido: os pés novos tinham um baixo valor, que acrescia substancial e progressivamente a partir do momento em que, com três anos, vingavam e começavam a produzir, atingindo seu preço máximo entre oito e dezesseis anos; daí em diante, com a queda de produtividade decorrente do envelhecimento e da erosão, o valor despencava, voltando, quando o cafezal em questão ultrapassava vinte e cinco anos de idade, ao ponto inicial ${ }^{18}$. Tal curva era expressão evidente de um sistema agrário devastador, que dependia do replantio constante dos pés de café em matas de derrubada para manter a produção em patamares estáveis, substituindo-se periodicamente os cafezais velhos e improdutivos prestes a serem convertidos em pasto por novos cafezais ${ }^{19}$.

17 Agradeço a Adriano Novaes (Valença) e Leila Alegrio (Teresópolis), que gentilmente me cederam seus fichamentos dos inventários dos Rio Preto, atualmente depositados no Museu da Justiça do Rio de Janeiro e, em novembro de 2005, inacessíveis aos pesquisadores.

18 MELLO, Pedro Carvalho de. A economia da escravidão nas fazendas de café: 1850-1888. Rio de Janeiro: Programa Nacional de Pesquisa Econômica, 1984. v.2, p. 15; LAËRNE, C.F. van Delden. Brazil and Java: report on coffee-culture in America, Asia, and Africa. Londres-Haia: Martinus Nijhoff, 1885. p.297.

19 STEIN, Stanley J. Vassouras: um município brasileiro do café, 1850-1900. (trad.port.) Rio de Janeiro: Nova Fronteira, 1990. p. 260-5; FRAGOSO, João Luis Ribeiro. Sistemas agrários em Paraíba do Sul (1850-1920). 1983. Dissertação (Mestrado) - Instituto de Filosofia e Ciencias Sociais, Universidade Federal do Rio de Janeiro, Rio de Janeiro, 1983. 
É isso o que se lê no inventário de 1869 da fazenda Flores do Paraíso. Seus primeiros cafezais foram plantados na década de 1830, antes da aquisição da sesmaria das Flores por Custódio Guimarães. Assim que a unidade começou a ser montada, em 1843, houve plantio em larga escala de novos pés, nos morros denominados como "das Flores" (plantado ainda em 1843), "do Açude" e "dos Mineiros" (ambos plantados em 1850). Segundo informação de Roberto Guião de Souza Lima, que atualmente escreve uma história da fazenda, o morro das Flores localizavase próximo à sede da fazenda Luanda, uma outra propriedade de Guimarães vizinha à Paraíso, não aparecendo no quadro de Facchinetti; muito provavelmente, o beneficiamento de seus frutos ocorreu de início na fazenda Luanda; os cafezais do Açude e dos Mineiros, por sua vez, já foram plantados contíguos à sede da nova fazenda Flores do Paraíso (comunicação pessoal, julho de 2006). No inventário de 1876, desapareceu a referência ao cafezal do Açude, mas manteve-se a indicação dos pés do cafezal dos Mineiros, agora descritos como velhos.

Foi justamente este último cafezal, com mais de vinte e cinco anos de exploração, que Facchinetti representou. Ao anotar visualmente o que estava ocorrendo de fato na propriedade do segundo barão do Rio Preto ${ }^{20}$, o italiano dava a ver toda a lógica da formação da paisagem agrária do Vale do Paraíba (derrubada das matas, plantio alinhado vertical dos cafezais, exploração por cerca de um quarto de século, esgotamento das plantas, conversão dos cafezais envelhecidos em pasto), sem omitir seus resultados profundamente danosos, como o processo erosivo.

A devastação ambiental derivada das operações comandadas pelos senhores de escravos vale-paraibanos foi o elemento central de um outro quadro de Facchinetti, composto seis anos depois. Trata-se do óleo sobre tela da fazenda Monte Alto, ou Montalto, "pintado fielmente do natural de julho a agosto de 1881" a pedido de Mathias Gonçalves de Oliveira Roxo, como se pode ler nas palavras anotadas em seu verso pelo artista (Fig. 2). A família Oliveira Roxo era cliente há longa data do pintor. Em 1869, por exemplo, Facchinetti compusera um óleo sobre tela da fazenda Vargem Alegre, comissionada pelo pai homônimo de Mathias Gonçalves - barão de Vargem Alegre desde 1866 - para celebrar a construção do ramal da ferrovia D. Pedro II, que ligaria o en-

200 inventário da viscondessa do Rio Preto registrou a presença de 421.500 pés de café, em 1873, na Flores do Paraíso. No inventário de seu filho, observa-se que houve uma expansão de 17\% no plantio de novos cafezais, que certamente se destinavam a substituir 106.000 pés descritos como "velhos" e prestes a se tornarem pasto, ou cerca de $25 \%$ do total inventariado três anos antes, em 1873. 
troncamento de Barra do Piraí ao município de Barra Mansa e que teria como primeira parada justamente sua fazenda ${ }^{21}$.

0 que importa aqui é o quadro da Montalto, localizada na então freguesia das Dores, município de Piraí (atual Dorândia, Barra do Piraí). 0 ponto de vista foi o mesmo que Facchinetti usara para a composição do óleo da Flores do Paraíso, isto é, a adoção de uma perspectiva panorâmica para se obter efeito cenográfico. E, tal como na peça de 1875 , as instalações da sede ocupam posição secundária na paisagem, que centra o olhar na topografia. A organização do espaço da representação também seguiu princípios análogos. A contraposição básica, no caso da Montalto, ocorre entre a parte esquerda e a parte direita do quadro, divisão marcada ao centro pela elevação que dera nome à fazenda. Na parte esquerda, o tema é dado, novamente, pela sede da fazenda em operação, como se nota pelo café disperso no terreiro, mas a ruína causada pela atividade cafeeira volta a chamar a atenção: para além dos cafezais detalhados no primeiro plano, vêem-se no plano ao fundo a terra desnuda, já convertida em pasto, e uma imensa voçoroca. 0 efeito de desolação é o aspecto mais relevante da parte direita do quadro, que igualmente narra a história da ocupação agrária do Vale: matas que são derrubadas para o plantio vertical do café, o que, em no máximo três décadas, dá origem ao mar de morros desnudos que se vê ao fundo da tela.

0 elemento que unifica toda a composição é, portanto, o processo de devastação causado pela atividade cafeeira, o que de saída coloca um problema para o investigador: por que o fazendeiro que encomendou o quadro aceitou a apresentação de sua unidade rural nesses termos? Seria esta uma representação efetiva do que era a fazenda em 1881 ?

A pergunta relativa ao referente é importante, pois pode ajudar a responder à primeira indagação. Para tanto, vale tentar estabelecer a trajetória da fazenda com as poucas informações de que se dispõe. Um bom caminho para isso consiste em acompanhar as listagens de fazendeiros de café do município de Piraí presentes no Almanak Laemmert da província do Rio de Janeiro ao longo da segunda metade do século XIX ${ }^{22}$. Mathias Gonçalves de Oliveira Roxo (pai) foi listado como fazendeiro de café no município desde o primeiro ano de publicação do suplemento provincial daquele que era um dos principais veículos de representação social no Império do Brasil. De fato, já em 1846

21 MARTINS, Carlos; PICCOLI, Valéria (Org.). Facchinetti. Rio de Janeiro:

CCBB, 2004. p. 14.

22 A coleção completa do Almanak Laemmert encontra-se disponível em http:// www.crl.edu/content/almanak2.htm. 
Oliveira Roxo apareceu como cafeicultor na freguesia da vila de Piraí, mas somente aí. Em 1852, ano em que nasceu seu filho homônimo, foi pela primeira vez listado como fazendeiro na freguesia das Dores, e, em 1856, também no arraial dos Thomazes. No longo período de 1857 a 1871, Mathias Gonçalves de Oliveira Roxo fez acrescentar ao seu nome ou a seu título (barão da Vargem Alegre), quando arrolado como cafeicultor na freguesia das Dores (mas não na da Vila e no arraial dos Thomazes), a relação de três fazendas: Onças, Minhocas e Canto-Alegre. Infelizmente, não há informações sobre o município de Piraí no Laemmert provincial de 1872, 1873 e 1874 . No ano seguinte, o barão da Vargem Alegre continuava a ser listado como fazendeiro em diferentes freguesias de Piraí, dentre as quais a das Dores, mas, pela primeira vez desde 1857 , sem a nomeação das propriedades. A novidade ficou por conta de Mathias Gonçalves de Oliveira Roxo (filho), então com 23 anos, aparecendo pela primeira vez como fazendeiro de café na freguesia das Dores, ao lado de seu irmão, Frederico Gustavo de Oliveira Roxo.

Por que, após 1875, não foram mais citadas as fazendas que o barão de Vargem Alegre possuía na freguesia das Dores? A resposta se encontra em seu necrológio publicado em 1880, onde se lê que alguns de seus "importantes estabelecimentos agrícolas" já eram "propriedades de seus filhos antes de seu passamento", em setembro de $1879^{23}$. De tudo isso, pode-se inferir que uma das três fazendas do barão de Vargem Alegre na freguesia das Dores foi legada a Mathias Gonçalves filho entre 1871 e 1875, como parte do adiantamento da herança. Aliás, é bem provável que se tratasse da fazenda da Onça, que teria sido então rebatizada como Montalto: um levantamento topográfico feito em 1988 indicou que era exatamente o rio das Onças que alimentava a propriedade, correndo canalizado em um grande muramento de pedra paralelo ao terreiro (Dossiê Fazenda Monte Alto - Arquivo Roberto Guião). Seja como for, tais informações indicam que a fazenda retratada por Facchinetti no início da década de 1880 fora fundada como uma unidade cafeicultora "satélite", dentro de complexo de fazendas do futuro barão da Vargem Alegre, ainda na década de 1850. 0 fato de não ser 0 centro das operações do patriarca dos Oliveira Roxo não significava que a fazenda fosse de menor importância, como davam a ver no quadro de Facchinetti o terreiro de pedra, o engenho de café com dois pavimentos ao centro do conjunto e a grande senzala localizada defronte a ele, no outro lado do terreiro. A

23 NECROLOGIO das casas titulares. ALMANAK Laemmert. Rio de Janeiro, 1880. p. 73. Disponivel em: http://www.crl.edu/content/almanak2.htm. Acesso em: 15 dez. 2006. 
casa de vivenda, modesta em 1881, passou por considerável ampliação após Mathias Gonçalves receber o título de barão de Oliveira Roxo, em setembro de 1882, sendo finalizada em 1885 (Dossiê Fazenda Monte Alto - Arquivo Roberto Guião). Nessa altura, contudo, seus cafezais deveriam estar bastante envelhecidos, após três décadas de exploração contínua; daí o registro desolador da paisagem de Facchinetti.

A análise dos quadros das fazendas Flores do Paraíso e Montalto recoloca o problema salientado antes: como entender o registro explícito da devastação ambiental contido em imagens encomendadas pelos próprios fazendeiros? 0 contraste entre Facchinetti e Grimm, neste aspecto, é realmente notável.

Com efeito, Johann Georg Grimm seguiu princípios distintos para a composição de suas paisagens das fazendas de café. Sua inscrição no mercado artístico brasileiro foi bem mais tardia do que a de Facchinetti. Chegando ao Rio de Janeiro em 1878, com sólida formação na Academia de Belas Artes de Munique, Grimm pintou sua primeira paisagem de fazenda - a das Águas Claras, na freguesia de São José do Rio Preto, município de Sapucaia - já no ano seguinte, por encomenda de Guilherme Augusto de Souza Leite, que a herdara naquela década de seu pai, Domingos de Souza Leite. A peça obedeceu a várias das características que marcaram a produção posterior de Grimm no Brasil: a adoção de um ponto de vista horizontal, que inseria o observador dentro, e não fora da cena representada; a inscrição de personagens na paisagem, em atitudes prosaicas e despojadas; o jogo de sombras ao longo do quadro, sem adotar a rígida hierarquização em três planos ${ }^{24}$. A horizontalidade na representação da fazenda das Águas Claras, além do mais, retirava de cena as referências diretas às suas atividades produtivas; nada, portanto, de pés alinhados nos morros (apreendidos em rápidas pinceladas, que davam apenas a idéia do volume) ou de grãos secando no terreiro ${ }^{25}$.

No que se conhece das pinturas de fazenda de Georg Grimm, contudo, Águas Claras representa a exceção, e não a regra. Logo ele adotou para o tema um outro tipo de registro. 0 primeiro quadro desta série é a fazenda Retiro (Fig. 3), localizada na freguesia de Bemposta, então no município de Paraíba

24 BELlUZZO, Ana Maria de Moraes. O Brasil dos viajantes. São Paulo: Metalivros-Odebrecht, 1994, v. 3. p. 146-9; LEVY, Carlos Roberto Maciel. O grupo Grimm: paisagismo brasileiro no século XIX. Rio de Janeiro: Edição Pinakotheke, 1980. p. 21.

250 quadro, um óleo sobre tela com 47,5 por $66,5 \mathrm{~cm}$, pertencente à Coleção Fadel, encontra-se reproduzido em BUENO, Alexei. O Brasil do século XIX na coleção Fadel. Rio de Janeiro: Edições Fadel, 2004. p. 186-87. 
do Sul. A unidade fora fundada em meados do século XIX, resultado de um desmembramento das propriedades de Antonio Luiz dos Santos Werneck, patriarca de um dos ramos mais importantes da família Werneck e falecido em $1848^{26}$. A Retiro coube a Manoel Luis dos Santos Werneck, que, desde 1852, foi listado no Laemmert provincial como dono da fazenda. Após seu falecimento, em 1874, a fazenda passou a seu filho, José Joaquim dos Santos Werneck, mas o inventário só foi concluído em $1880^{27}$. Observa-se, neste caso, o mesmo que ocorreu na produção dos óleos das fazendas Flores do Paraíso e Montalto: como meio de auto-afirmação e reiteração da memória familiar, o filho, ao assumir a herança do pai, encomendou a composição de uma paisagem da fazenda.

0 foco de Grimm, ao retratar a Retiro, recaiu sobre a implantação do conjunto arquitetônico da fazenda, em um tipo de registro denominado como "documental" 28 . A adoção de um ponto de vista vertical, tomado do alto de um morro, não conduz - ao contrário do que ocorre em Facchinetti - a uma visão panorâmica, mas antes ao espaço compactado da sede, algo que se ressalta ainda mais por meio da divisão da tela e de seu respectivo jogo de cores. 0 quadro é cindido horizontalmente em duas partes. A metade superior divide-se simetricamente entre céu e morro, diferenciados pelo vivo contraste entre azul e verde, sendo a metade inferior preenchida pela casa de vivenda, pelo engenho, pela tulha, pelas senzalas dispostas em quadra, pelos terreiros e pelo cercado para os animais. Destaca-se, nesta parte, a área ocupada pelos terreiros, cuja centralidade para as operações da fazenda é salientada por meio da representação das atividades dos escravos na secagem dos grãos, em trabalho coletivo rigidamente coordenado.

No entanto, se o café está presente na esfera do beneficiamento, não há referência direta ao seu cultivo. Na composição da paisagem, Grimm anotou apenas a presença de matas e pastos, como se a passagem fosse natural e não estreitamente articulada à montagem dos cafezais, ao progressivo envelhe-

26 SILVA, Eduardo. Barões e escravidão: três gerações de fazendeiros e a crise da estrutura escravista. Rio de Janeiro: Nova Fronteira-INL, 1984. p. 54; e SILVA, Pedro Gomes da. Capítulos da história de Paraíba do Sul. Paraíba do Sul: Editora Companhia de Artes Gráficas, 1991. p. 137-40.

27 FRAGOS0, João Luis Ribeiro. Sistemas agrários em Paraíba do Sul (18501920). 1983. Dissertação (Mestrado) - Instituto de Filosofia e Ciencias Sociais, Universidade Federal do Rio de Janeiro, Rio de Janeiro, 1983. p. 77.

28 LEVY, Carlos Roberto Maciel. 0 grupo Grimm: paisagismo brasileiro no século XIX. Rio de Janeiro: Edição Pinakotheke, 1980. p. 31-2. 
cimento das plantas e à devastação ambiental. Tal processo de transformação, no caso da fazenda Retiro, havia chegado a um patamar agudo em 1881. Conforme indicou a análise de João Fragoso ${ }^{29}$, entre 1878 e 1880 o número total dos pés de café da fazenda caiu de 98.500 para 54.500; em 1876, foram plantados 12.000 pés, que, no entanto, não seriam capazes de manter a produção em patamares estáveis. 0 freio à produção da fazenda era dado, claramente, pelo esgotamento de suas reservas de mata virgem.

0 óleo que Grimm compôs para a fazenda Retiro, ao lado de sua meteórica carreira no mercado artístico da corte, parecem ter chamado a atenção dos Santos Werneck. Em 1882, após haver apresentado 128 peças no salão independente promovido pela Sociedade Propagadora das Belas Artes, Grimm obteve tal repercussão com sua obra que acabou sendo convocado pelo próprio D. Pedro II para assumir a cadeira de Paisagem, Flores e Animais na Academia Imperial de Belas Artes. Grimm aí lecionou até 1884, quando, diante da forte oposição interna, resolveu deixar a instituição, sendo acompanhado por vários de seus alunos. Mestre e discípulos, reunidos entre 1884 e $1887 \mathrm{em}$ Niterói, viriam a constituir o famoso Grupo Grimm, que tanto marcou a história da pintura de paisagem no Brasil. Foi nessa fase que o artista alemão compôs a maior parte dos quadros de fazendas de café que atualmente se conhece de sua lavra ${ }^{30}$.

Somente para o ramo Santos Werneck, Grimm preparou mais três peças, todas de fazendas muito próximas umas das outras, entre as freguesias de São José do Rio Preto (Sapucaia) e Bemposta (Paraíba do Sul): fazenda Sant’Anna do Calçado, pertencente ao Barão de Bemposta, Ignácio Barbosa dos Santos Werneck (óleo sobre tela, 74 x $51 \mathrm{~cm})^{31}$; fazenda do Recreio, pertencente a Francisco Inácio dos Santos Werneck (óleo sobre tela, 38 x 52,5 cm); fazenda Cataguá, pertencente a Fernando Luiz dos Santos Werneck (óleo sobre tela, 82,5 x $128 \mathrm{~cm}$ ). Não se sabe ao certo a data do primeiro quadro, mas os dois últimos foram compostos, respectivamente, em junho e dezembro de 1886, todos os três seguindo sempre o mesmo padrão pictórico adotado para a fazenda Retiro.

29 FRAGOSO, João Luis Ribeiro. Sistemas agrários em Paraíba do Sul (18501920). 1983. Dissertação (Mestrado) - Instituto de Filosofia e Ciencias Sociais, Universidade Federal do Rio de Janeiro, Rio de Janeiro, 1983. p. 77.

30 LEVY, Carlos Roberto Maciel. O grupo Grimm: paisagismo brasileiro no século XIX. Rio de Janeiro: Edição Pinakotheke, 1980. p. 21-32.

31 O café: catálogo da exposição realizada na Praça do Banco Real. São Paulo: Banco Real-ABN-AMRO Bank, 2000. p. 80-1. 
A paisagem que melhor o sintetiza é a da fazenda Cataguá (Fig. 4). 0 quadro foi dividido por Grimm em quatro partes bem evidentes. 0 quarto superior é ocupado pelo céu; o inferior, por uma paisagem campestre ordinária que bem poderia ser tomada como uma vista da terra natal de seu autor. 0 que realmente importa está no miolo do quadro, que, por seu turno, separa-se em dois triângulos retangulares e opostos. 0 primeiro procura representar o processo produtivo do café e o conjunto arquitetônico da fazenda - o tema central da composição. Assim, vemos no morro à direita o alinhamento rigoroso dos pés de café recém-plantados, capinados por um terno de escravos comandados em uníssono por um feitor que se localiza abaixo, na primeira vertente do caminho que sobe ao alto da elevação. 0 eixo diagonal desse morro constitui a hipotenusa do primeiro triângulo; o cateto vertical é fornecido pela própria moldura e o horizontal, pela linha das construções da sede. Ao observador é dado ver todos os edifícios que a compunham: casa de vivenda, senzala em quadra, tulhas, engenho, terreiros. Nestes, a atividade é intensa, pois diversos escravos, igualmente labutando em linha, espalham os grãos para a secagem. 0 segundo triângulo, cujo cateto horizontal é marcado pelo traço que separa a terra do céu, tem um outro referente, que expressa o ponto de partida e o ponto de chegada do processo mais amplo de formação da paisagem da zona de cafeicultura do Vale do Paraíba: a contínua transformação de matas em pastos.

Afora a ênfase que concede à arquitetura e a ausência de um sentido panorâmico, Grimm apresenta nesses quadros uma outra diferença decisiva em relação a Facchinetti: ao registrar o processo de formação da paisagem, o alemão não revela as marcas visíveis da devastação ambiental, como as erosões e as voçorocas expostas nos quadros do italiano. Há, neste silêncio, um problema adicional que diz respeito ao seqüenciamento matascafezais-pastos. Tal como a Retiro, a fazenda Cataguá vinha sendo explorada de forma ininterrupta desde meados do século XIX, como indicava o arrolamento de Fernando Luiz dos Santos Werneck como seu dono no Laemmert provincial a partir de 1855. Ora, após três décadas de atividade, ou os pés de café vizinhos à sede - os primeiros morros cultivados com o arbusto eram sempre os que ficavam mais próximos - estariam em estado deplorável, como o pincel de Facchinetti anotou para a fazenda Montalto, ou já teriam sido arrancados e convertidos em pasto, como o próprio Grimm exprimiu para a fazenda Retiro. A presença de morros pelados, cobertos de pasto e contíguos às sedes das propriedades cafeeiras vale-paraibanas é visível em todas as fotografias que Marc Ferrez tirou na década de 1880. Como, então, explicar a inscrição de um cafezal recém-plantado no quadro da Cataguá, atrás da sede, onde jamais ele poderia estar em $1886 ?$ 


\section{A crise da escravidão e as pinturas de paisagem}

Logo após chegar ao Brasil, em 1849, Facchinetti começou a oferecer seus serviços de retratista e pintor de paisagens por meio das páginas do Almanak Laemmert. A inscrição no mercado artístico do Rio de Janeiro passava, necessariamente, pela participação nas exposições gerais organizadas pela Academia Imperial de Belas Artes. Sua primeira experiência nesse espaço institucional, contudo, não foi bem sucedida, pois os trabalhos que apresentou na 11 ${ }^{\text {a }}$ Exposição Geral (1850) receberam duras críticas na imprensa. Nos quinze anos seguintes, Facchinetti foi figura menor no mercado carioca, dando aulas particulares de desenho e de italiano e trabalhando como cenógrafo na montagem de peças teatrais e em festividades. Sua carreira deslanchou efetivamente a partir de meados da década de 1860, ao participar com sucesso da 16a Exposição Geral (1864) e ao obter diploma oficial da Academia de Belas Artes (1865) para lecionar a arte do desenho ${ }^{32}$.

0 estabelecimento no mercado artístico do Rio de Janeiro dependia, então, da estrita obediência ao receituário estético da Academia Imperial, algo ainda mais premente para aqueles que operavam fora de seus quadros. Valéria Piccoli chamou a atenção para esse aspecto, ao ressaltar que a obra de Facchinetti

se alinha à definição cunhada pela Academia de que a pintura brasileira deveria se fundar no tema da cultura que age sobre e transforma o mundo natural. Num olhar geral, nota-se que não são as paisagens naturais, a floresta virgem ou o aspecto ainda primitivo da natureza brasileira - tão prezados por estrangeiros em visita ao país - que atraem seu interesse. [...] 0 que parece interessar a Facchinetti sobretudo é a paisagem trabalhada pelo homem. Nesse sentido, suas obras mais notáveis são sem dúvida as pinturas de fazenda que executou a partir do final dos anos $60 .^{33}$

32 URCCI, Michelle Yara. A paisagem de Nicolau Antonio Facchinetti no Brasil do século XIX. 2003. 181 f. Dissertação (Mestrado em Sociologia) - Faculdade de Filosofia, Letras e Ciências Humanas, Universidade de São Paulo, São Paulo, 2003. p. 81. CHIAVARI, Maria Pace. A síntese de dois mundos na paisagem de Facchinetti. In: MARTINS, Carlos; PICCOLI, Valéria (Org.). Facchinetti. Rio de Janeiro: CCBB, 2004. p. 42-4.

33 PICCOLI, Valéria. Visão natural e artifício na pintura de Facchinetti. In: MARTINS, Carlos; Piccoli, Valéria (Org.). Facchinetti. Rio de Janeiro: CCBB, 2004. p. 33. 
0 trecho fornece uma boa chave para compreender o tema da transformação da natureza em Facchinetti. Com efeito, escapou à autora a existência, desde a década de 1840, de uma importante linha de crítica ambiental dentro da própria Academia Imperial de Belas Artes e que acabou ressoando na produção do artista italiano. Essa vertente se expressou nas obras de alguns dos principais membros da Academia. Félix-Émile Taunay, por exemplo, ao inserir comentário explicativo sobre sua Vista de um mato virgem que se está reduzindo a carvão no catálogo da Exposição Geral de 1842 , escreveu que

a desaparição dos mais belos exemplares do reino vegetal nos arredores da Cidade ameaça a esta, segundo cálculos irrefragáveis, com diminuição das águas vivas e elevação do grau médio de calor, dois males reciprocamente ativos. ${ }^{34}$

Do mesmo modo, Manuel de Araújo Porto-Alegre, em seu longo poema $A$ destruição das florestas redigido em 1845, apontou os efeitos profundamente danosos do uso irracional e desmedido das reservas de mata virgem na expansão agrícola em zonas de fronteira ${ }^{35}$.

É bom que se diga que a crítica ambiental encontrou espaço não apenas na Academia de Belas Artes, mas também em outras instituições que gozavam de igual prestígio no Brasil monárquico, como o Imperial Instituto Fluminense de Agricultura, fundado em 1860 e que muito tratou das técnicas adotadas nas fazendas do Vale do Paraíba. Essa tradição intelectual, além do mais, alcançou uma notável realização prática entre 1862 e 1887, quando se promoveu o reflorestamento do maciço da Tijuca, após décadas de desmatamento para abastecer o mercado urbano do Rio de Janeiro com lenha e, sobretudo, para se plantar café. Facchinetti certamente acompanhou de perto tais esforços; afinal, como bem lembrou o historiador José Augusto Pádua,

o verde das montanhas de Santa Teresa e da Tijuca tinha um significado importante na vida cultural e artística da capital, servindo de inspiração para vários trabalhos de pintura e literatura. ${ }^{36}$.

34 DIAS, Elaine C. A pintura de paisagem de Félix-Émile Taunay. Rotunda, Campinas, v. 1, p. 5-18, abr. 2003. Disponível em: <http://www.iar.unicamp. $\mathrm{br} /$ rotunda/rotunda01.pdf $>$.

35 PÁDUA, José Augusto. Um sopro de destruição: pensamento político e crítica ambiental no Brasil escravista (1786-1888). Rio de Janeiro: Jorge Zahar Editor, 2002. p. 162-6.

36 Ibid. p. 221. 
Enfim, tudo isso indica que havia aberturas para a crítica ambiental na segunda metade do século XIX, fornecidas em parte pela própria prática artística da Academia Imperial de Belas Artes. Facchinetti, ao anotar o esgotamento do solo e a erosão em suas paisagens das fazendas de café, dialogou diretamente com essa linhagem.

Esse elemento ajuda a explicar o número relativamente pequeno - considerando-se o que atualmente se conhece da obra de Facchinetti - de paisagens de fazendas de café por ele compostas. É certo que, como se leu na introdução do texto, o gênero não foi da predileção das classes senhoriais do centro-sul do Brasil ao longo do século XIX. Mesmo assim, salta aos olhos o fato de Facchinetti ter composto, em meio século de trabalho no mercado fluminense, menos de uma dezena de óleos sobre o tema. A prática social e cultural dos senhores de escravos do Vale do Paraíba promoveu uma ordenação do espaço simbólico da fazenda de café que, ao menos até a década de 1880, não demandou sua representação em pinturas de paisagem; quando isso se deu, o registro ocorreu em um sentido bastante distinto do que expressava Facchinetti em seus quadros. Basta lembrarmos o caso da famosa pintura parietal da fazenda Resgate, em Bananal, província de São Paulo, composta provavelmente na segunda metade da década de 1850 por José Maria Villaronga ${ }^{37}$. Recorrendo a um artifício que esteve na origem renascentista da pintura de paisagem, o pintor abriu a "janela" da sala de jantar da casa de vivenda da fazenda Resgate para as linhas verticais dos cafezais perfeitamente simétricos, cujo produto fluía como que naturalmente, sem a necessidade de trabalho humano, para os cofres de seu proprietário.

Muita coisa mudou na virada da década de 1870 para a de 1880. Facchinetti parece não mais ter recebido encomendas para elaborar paisagens de fazendas de café após a finalização do quadro da Montalto, em 1881. Por outro lado, ainda que Grimm tenha pintado ao menos uma fazenda - a Águas Claras - entre 1879 e 1880 , a maior parte dos quadros sobre o tema de sua autoria foram realizados após 1881, e, em especial, em 1886. Ora, esses anos marcaram uma inflexão decisiva nas expectativas dos fazendeiros do Vale do Paraíba quanto ao futuro da escravidão. Desde a promulgação da Lei do Ventre Livre, em 1871, sabia-se que a longo prazo a instituição estava condenada no Brasil. A oposição dos representantes dos cafeicultores do Vale do Paraíba ao projeto de lei, por ocasião dos debates

37 FRAGOSO PIRES, Fernando Tasso. Fazendas: solares da região cafeeira do Brasil Imperial. Rio de Janeiro: Nova Fronteira, 1990. p. 86. 
parlamentares, foi ferrenha, e sua aprovação em 28 de setembro daquele ano representou, na feliz expressão de José Murilo de Carvalho, "a primeira clara indicação de divórcio entre o Rei e os barões" ${ }^{38}$. De fato, toda a estrutura política que sustentava o Império começou a manifestar sinais de crise com a passagem da lei ${ }^{39}$. Não obstante, a lei rapidamente foi instrumentalizada pelos porta-vozes dos senhores de escravos para a defesa do cativeiro, sob o argumento de que ela significava a última palavra da Coroa frente à questão ${ }^{40}$. Tal estratégia, se bem funcionou nos anos 1870, alimentando o volumoso tráfico interno de escravos no Império, fracassou na década subseqüente. A articulação política do movimento abolicionista a partir de 1879 colocou em xeque os fazendeiros de café. Dentre as respostas que encontraram nos anos seguintes, esteve a suspensão do tráfico interprovincial, vista como uma medida que garantiria o apoio das províncias exportadoras de cativos à causa escravista dos cafeicultores do centro-sul. 0 efeito, contudo, foi inverso ao que planejavam, pois entre 1881 e 1883 ocorreu o virtual colapso do mercado interno de escravos no Brasil, com a queda abrupta e irreversível dos preços dos cativos, o que, em si, expressava a expectativa profundamente negativa dos agentes econômicos quanto ao futuro próximo da instituição ${ }^{41}$. 0 prognóstico pessimista foi ainda mais acentuado na década de 1880 pela percepção senhorial da crescente insurgência escrava, que ques-

38 CARVAlHo, José Murilo de. A construção da ordem/Teatro de sombras. 4. ed. Rio de Janeiro: Civilização Brasileira, 2006. p. 322.

39 COSTA, Emília Viotti da. Brasil: a era da reforma, 1870-1889. In: BETHELL, L. (Org.) História da América Latina. São Paulo: Edusp-Funag, 2002. v. 5: de 1870 a 1930. p. 734-7.

40 CONRAD, Robert. Os últimos anos da escravatura no Brasil. Rio de Janeiro: Civilização Brasileira, 1978. p. 145-6; e SLENES, Robert W. The brazilian internal slave trade, 1850-1888: regional economies, slave experience, and the politics of a peculiar market. In: JOHNSON, Walter (Ed.). The chattel principle: internal slave trades in the Americas. New Haven: Yale University Press, 2004. p. 357-8.

41 MELlo, Pedro Carvalho de. Aspectos econômicos da organização do trabalho da economia cafeeira do Rio de Janeiro, 1850-1888. Revista Brasileira de Economia, Rio de Janeiro, v. 32, n. 1, p. 19-67, jan.-mar. 1978; MELLO, Pedro Carvalho de; SLENES, Robert. Análise econômica da escravidão no Brasil In: NEUHAUS, P. (Org.) Economia brasileira: uma visão histórica. Rio de Janeiro: Campus, 1980. SLENES, Robert W. The brazilian internal slave trade, 1850-1888: regional economies, slave experience, and the politics of a peculiar market. In: JOHNSON, Walter (Ed.). The chattel principle: internal slave trades in the Americas. New Haven: Yale University Press, 2004. p. 357-8. 
tionava frontalmente os padrões de organização do processo de trabalho vigentes desde o início da cafeicultura ${ }^{42}$.

Foi nesse contexto de crise aguda que certos cafeicultores do Vale do Paraíba fluminense procuraram Georg Grimm para elaborar as vistas de suas fazendas. Ajustando-se à nova demanda, Grimm abandonou os princípios que seguira até então para a produção dos temas de sua preferência, como paisagens marinhas ou rochosas, e que, de certa forma, havia adotado para o caso da fazenda das Águas Claras. Como se viu, a partir da composição do óleo da fazenda Retiro, em 1881, o modelo empregado para tratar as fazendas de café foi outro, estritamente atinado à perspectiva de classe dos senhores de escravos valeparaibanos. Ao contrário de Facchinetti, que construiu sua carreira dialogando com os ditames da Academia Imperial de Belas Artes, Grimm teve uma trajetória que se opôs a ela. Sua saída turbulenta da instituição, em 1884, deveu-se entre outras coisas à resistência que encontrou em relação ao tipo de ensino da pintura de paisagem que propunha. 0 grupo que então montou com seus ex-alunos se caracterizou exatamente pela tentativa de criar alternativas ao que se praticava, no campo da pintura de paisagem, dentro da Academia Imperial de Belas Artes.

A ausência de compromisso com certas questões caras ao espaço institucional da Academia permitiu a Grimm encampar sem constrangimentos a concepção dos cafeicultores quanto à conformação da paisagem agrária do Vale do Paraíba, concepção esta que encarava a derrubada da mata, o plantio de café e, no limite, a formação de pastos como sinais de domesticação do mundo natural e, portanto, de progresso. 0 discurso visual que o pintor alemão expressou sobre o assunto nas telas das fazendas Retiro e Cataguá reproduziu à risca o discurso textual apresentado pelos fazendeiros havia décadas, baseado nas oposições binárias café x mata, cultura x natureza, civilização x barbárie. Basta lembrar, aqui, a fala do presidente da província do Rio de Janeiro, Paulino José Soares de Sousa, à Assembléia Provincial, em março de 1838:

o café desta Província, cuja concorrência no mercado estrangeiro era no ano de 1810 apenas sensível, forma hoje o seu principal ramo de exportação, a qual presentemente excede

42 COSTA, Emília Viotti da. Da senzala à colônia. 3. ed. São Paulo: Brasiliense, 1989. p. 335-48; e MACHAD0, Maria Helena P.T. O plano e o pânico: os movimentos sociais na década da abolição. São Paulo: Edusp; Rio de Janeiro: Editora UFRJ, 1994. 
a muito mais de dois milhões e trezentas mil arrobas, quase todas de primeira qualidade. Sertões, outrora incultos, ermos e cobertos de matas virgens, acham-se hoje em grande parte roteados, povoados e cobertos de estabelecimentos rurais, que daqui a alguns anos poderão talvez dobrar ou triplicar a nossa exportação e atual riqueza. ${ }^{43}$

Mas não só. Como resposta a um mundo que estava desmoronando rapidamente por conta da ação do movimento abolicionista e dos próprios trabalhadores escravizados, Grimm oferecia aos fazendeiros uma representação de suas unidades que traduzia ordem, hierarquia e disciplina. Daí a ênfase na implantação arquitetônica, com a exata disposição das senzalas em quadra, solução criada na primeira metade do século XIX para controlar rigidamente a circulação dos escravos; daí a representação do trabalho coletivo sob supervisão estrita, tanto nos terreiros como no campo; daí, finalmente, a deslocada inscrição de um cafezal recém-plantado contíguo à sede da velha fazenda Cataguá, sugerindo que a produção cafeeira seguia adiante, a despeito de tudo.

Não se sabe ao certo quantas paisagens de fazenda de café Grimm compôs na década de 1880; porém, não é arriscado afirmar que, em termos comparativos, sua produção sobre o tema foi mais volumosa que a de Facchinetti. 0 gênero da pintura de paisagem, assim, só foi ativado pelos cafeicultores do Vale do Paraíba no contexto da crise final da escravidão. Algo semelhante já havia ocorrido no Caribe inglês na década de 1820, quando, acuados pelo movimento antiescravista metropolitano e pela resistência escrava, seus proprietários encomendaram a composição de gravuras de paisagem - como o indicam as obras de William Clark (1823) e James Hakewill (1825) - que apresentavam uma clara defesa do universo das plantations açucareiras escravistas (gravuras disponiveis em http://hitchcock.itc.virginia.edu/Slavery/index.php). É bastante significativo que tenham sido os filhos dos primeiros fazendeiros que encomendaram essas pinturas. Tratava-se de um evidente esforço para registrar, em um quadro inerte, um mundo - como bem sabiam - prestes a ruir. Nada melhor, então, do que representar a memória da grandeza pretérita das fazendas em que haviam sido criados. 


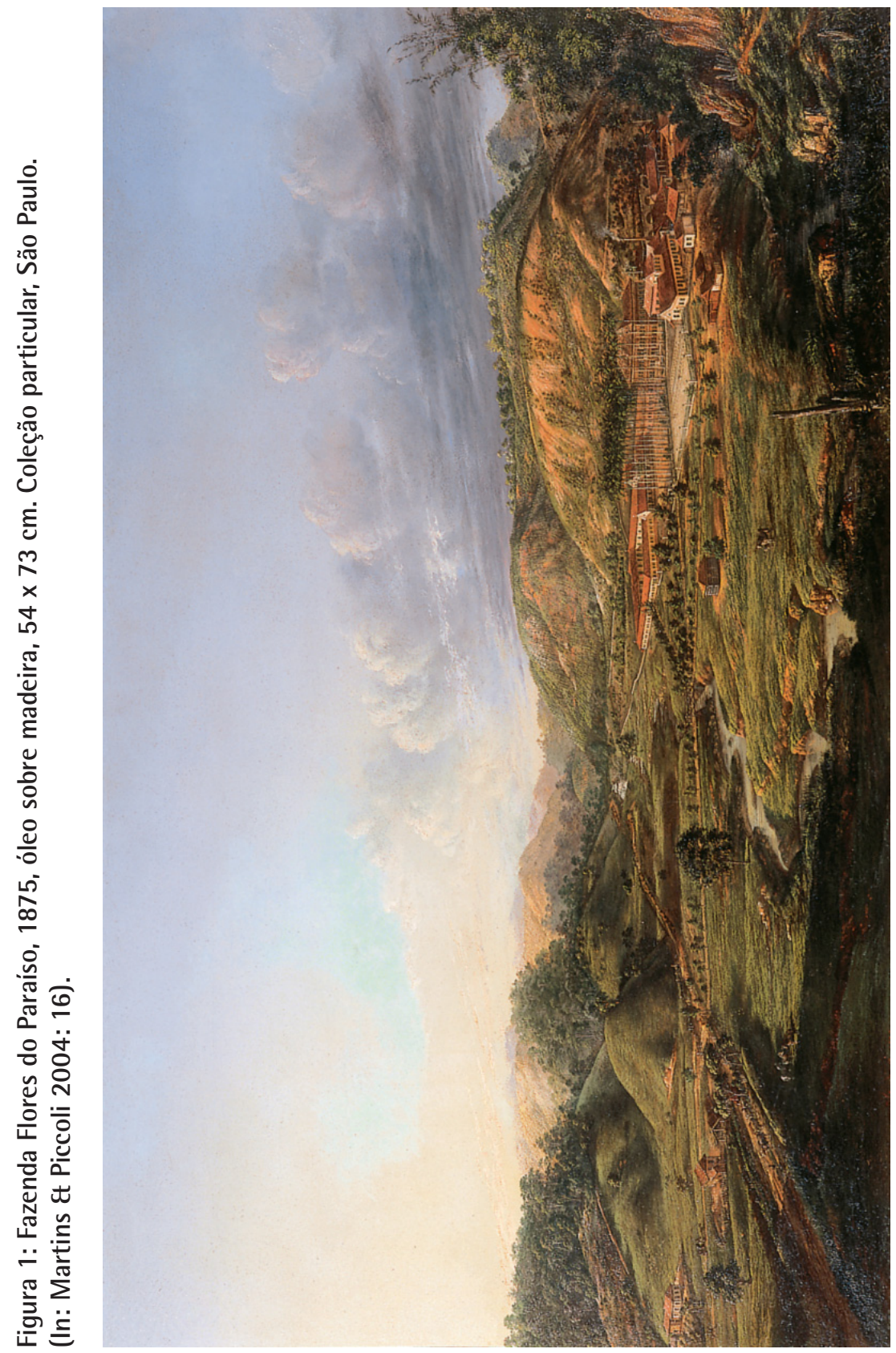

revista do ieb n 44 fev 2007 


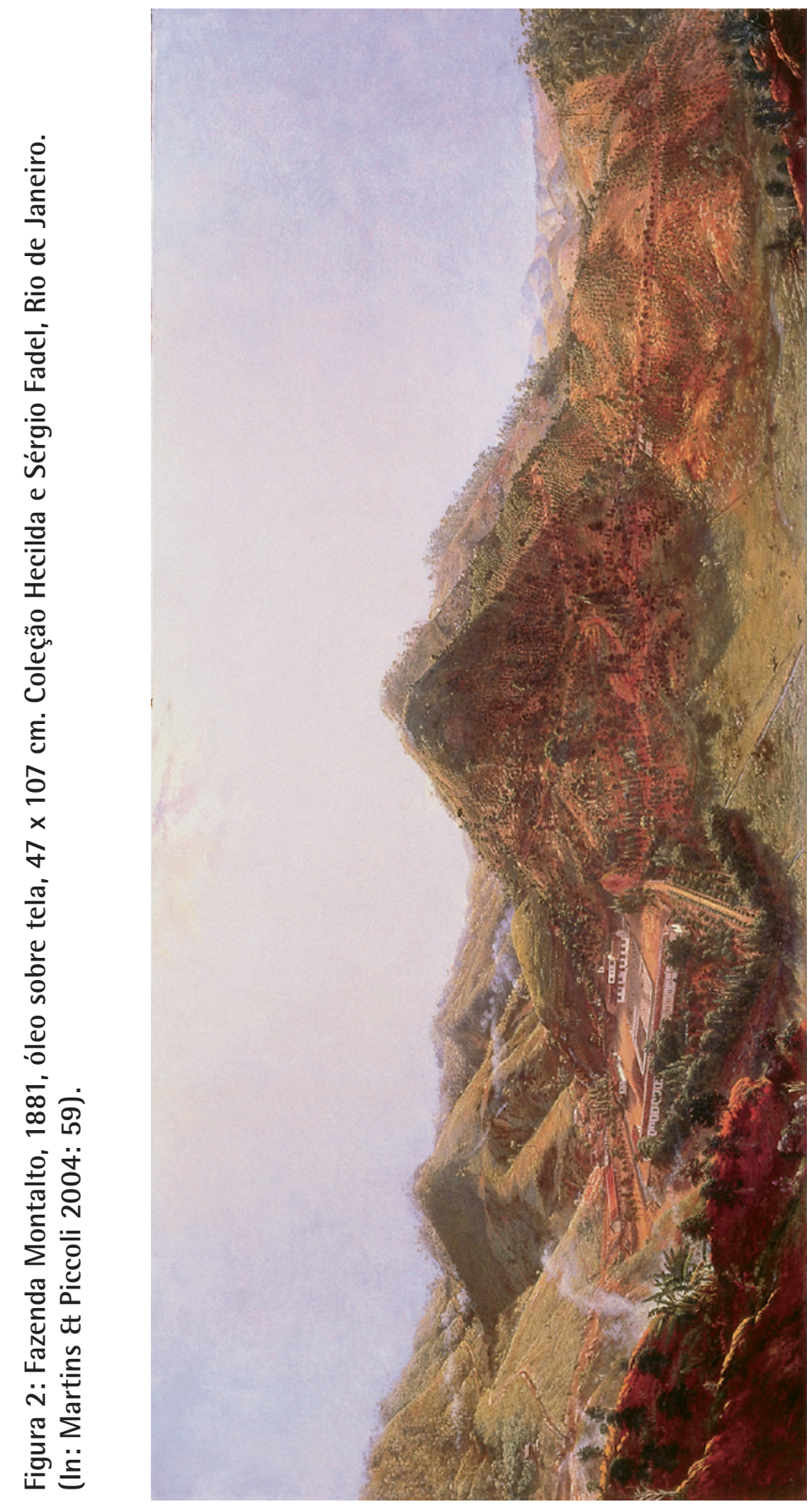




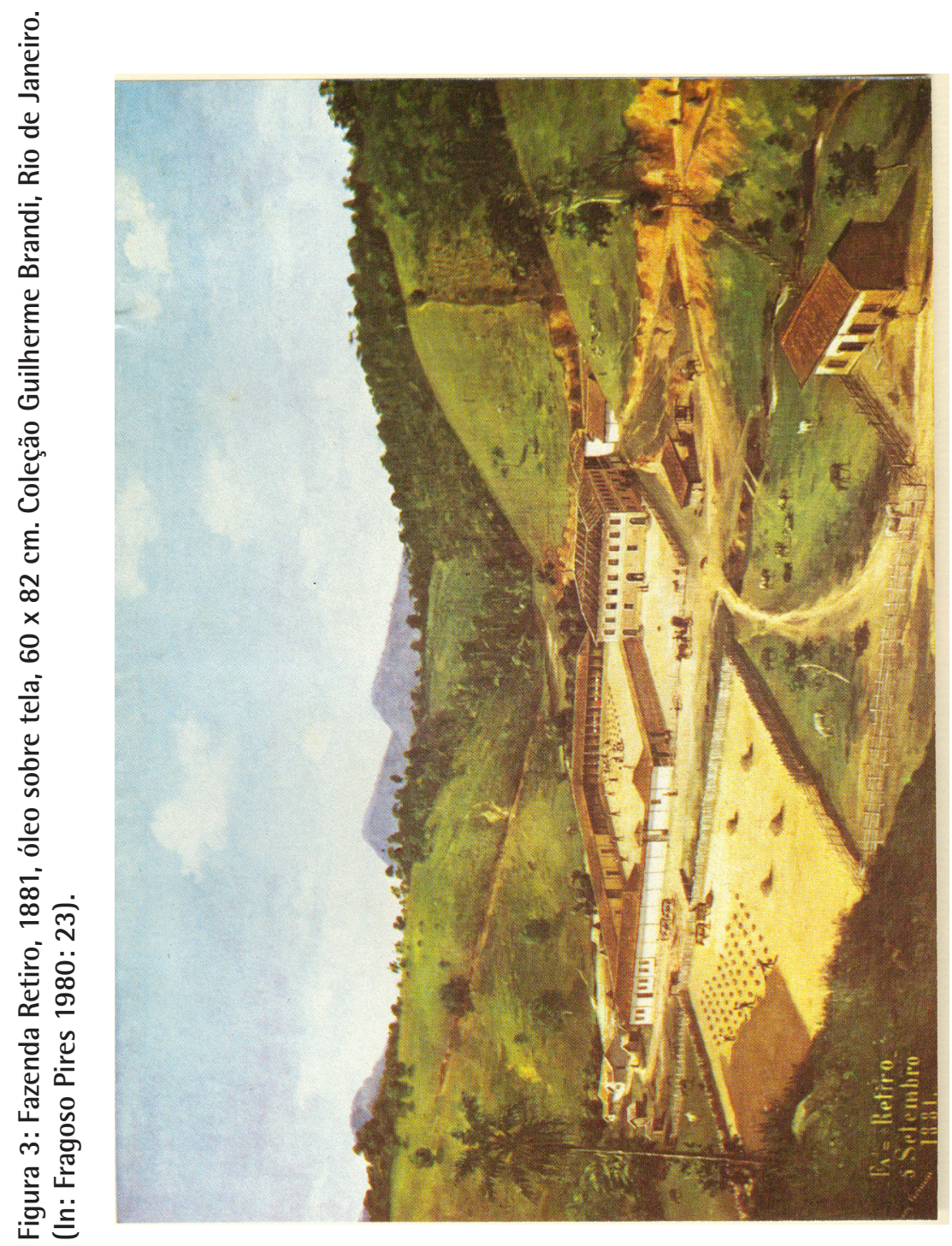

revista do ieb n 44 fev 2007 


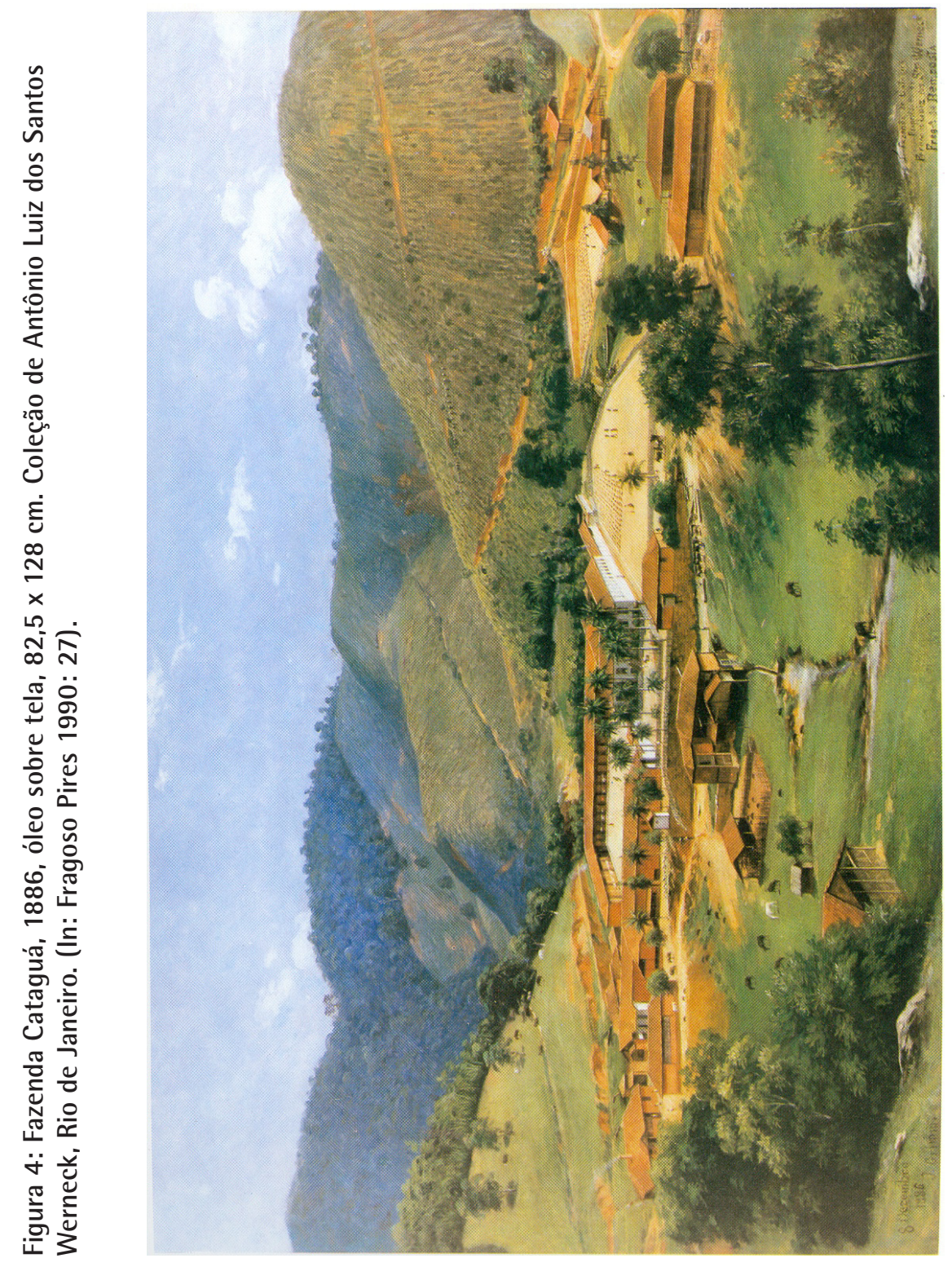

